\title{
A MORTE DO PACIENTE E SUA REPERCUSSÃO EM ESTUDANTES DE ENFERMAGEM
}

Maria Margarida da Cunha Gonçalves *

GONÇALVES, M. M. da C. - A morte do paciente e sua repercussão em estudantes de enfermagem. Rev. Esc. Enf. USP 10 (1):95-100 1976.

Relata experiência sobre a influência exercida pelo paciente moribundo e a morte, em um grupo de estudantes de enfermagem $e$ o trabalho realizado a fim de conduzi-lo a uma mudança de atitude e permitir um cuidado mats adequado das situaçzes referidas.

A morte 6, talvez, a situação mais difícil de ser enfrentada pelo pessoal médico e de enfermagem.

EISSLER (1965) afirma que a preocupação em controlar, combater a doença, pode ser o maior empecilho para o estudo e a compreensăo da morte. Quando esta ocorre, năo resta mais nada a fazer, năo há mais o que combater, controlar. Esta posição, comumente adotada pelo pessoal da equipe de saúde, 6 provavelmente o que faz com que haja tanta dificuldade quando se depara com a aproximagio da morte.

FRANCIS \& MUNJAS (1971), em um capítulo de seu livro onde sao focalizados cuidados de enfermagem ao paciente moribundo, dizem que, como as pessoas da equipo de saúdo preparam os pacientes para as cirurgias ou outras experièncias, devem prepará-los, de certa forma, para morrer. Continuando, alientam que a enfermeira, para que tenha uma aço efetiva no culdado com a morte, deve ter empatia, conhecimento o habilidade. Para que consiga so empatizar, 6 necesuário que seja capaz de projetar no paciente seus proprios sentimentos o sentir a mesma emoğo que está sendo expressa

\footnotetext{
- Auxiliar de Ensino da disciplina Fundamentos de Enfermagem de EEUSP.
} 
por ele. Empatia requer imaginação. Seria o tentar descobrir o que representa para aquele paciente, seus anos de vida, seus trabalhos, seus filhos, sua vida conjugal, sua religião. Tendo a capacidade de sentir o paciente, a enfermeira saberá se ele gostaria ou não de falecer sozinho, longe de sua casa, numa cama estranha e que providencias nesse sentido podem e devem ser tomadas.

Ao se iniciar o trabalho de campo com alunos de enfermagem, sentiu-se que ao primeiro contacto com o paciente considerado em estado grave, o aluno apresentava um comportamento de aparente incapacidade para prestar cuidados a esse doente.

No ensino no campo clínico, teve-se sempre a preocupação de reservar, diariamente, a última hora de estágio para a avaliação em grupo das tarefas realizadas. Tanto as experiências consideradas pelos alunos, positivas ou negativas, eram trazidas e analisadas. Percebeu-se no grupo, um clima de inquietação e tensão quando era focalizado o cuidado prestado a um paciente com possibilidade de iminente falecimento. Toda vez que um aluno passava pela experiência de morte e o tema era levantado, o grupo mostrava-se deprimido. Sentia-se que os mesmos não se haviam dado conta do motivo da tensão. Várias explicaçðes eram trazidas:

- O paciente necessita de muitos cuidados ao mesmo tempo, fico sem saber o que fazer primeiro...

- Meu paciente estava necessitando de muitos exames de laboratório para serem colhidos, perdi muito tempo com isso...

- O médico estava passando um intra-cath e eu não podia nem sequer chegar perto do doente...

A impressão que se tinha era de que o estudante passava a ignorar seus conhecimentos, sua destreza manual e seu desembaraço, quando se deparava com essa situação, nova e por ele desconhecida.

Certa vez, quando se apontou a uma aluna, uma falha em relação ao planejamento do cuidado de enfermagem de seu paciente, ela começou a chorar. $O$ grupo permanecia em silêncio. Sentia-se a tensão aumentar.

Ocorreu então perguntar ao grupo naquele momento, se aquele choro não estaria relacionado a tantas mortes presenciadas naquela semana de trabalho e o fato de não se ter ainda discutido como cada membro do gru- 
po encarava a morte de seus pacientes. A partir desse momento o grupo começou a falar, inicialmente com muita dificuldade. À medida que conseguiam expressar seus sentimentos, sentiu-se a tensão diminuir e todos puderam conversar. Os comentários eram os mais variados, porém se resumiam em insatisfação e não aceitação da morte dos pacientes.

Afinal de que adiantavam tantos cuidados, tantos médicos e enfermeiras preocupados com aquele ser, se sua morte era inevitável? $\mathrm{E}$ as aulas, onde os professores salientam a recuperaçăo e manutençăo da saúde? Será que năo estaria havendo uma omissão por parte dos docentes em preparar os estudantes para enfrentar a morte?

Poder-se-ia enumerar aqui diversos comportamentos observados neste grupo de alunos, pois foram inúmeras as ocasiðes onde eles necessitaram atuar junto ao paciente moribundo e mesmo observar sua morte.

Como exemplo; porém, será feito o relato de três experiências consideradas bastante significativas para todos os membros do grupo.

A primeira ocorreu com uma aluna que se destacava pela responsabilidade e coerência no trabalho de enfermaria.| Iniciou seus cuidados de enfermagem com um paciente que deveria ser operado brevemente. Empenhou-se em prepará-lo psicologicamente para a cirurgia, em virtude de suas condiçðes de saúde serem precárias e aquele tratamento cirárgico somente viria beneficiá-lo. $O$ paciente referia constantemente medo de vir a falecer em decorrência da cirurgia e atitude da aluna foi tentar diminuir sua preocupaço mostrando as vantagens daquele tratamento a ele.

Acontece que no primeiro dia de pós-operatório, a estudante encontra esse paciente muito grave e piorando gradativamente, apresentando complicaçð̄es pós-operatórias. Percebeu-se então que a aluna ñ̃o estava, ela propria, preparada para enfrentar uma situaçăo de piora do paciente. $\lambda$ medida que observava sua gravidade, mais dificuldade sentia em oxecutar seu trabalho junto a ele, chegando ao ponto de procurar a professora na enfermaria dizendo não ter condiçōes emocionais para cuidar do paciente. Pediu que se colocasse uma colega em seu lugar. Ach condiços para ser enfermeira o que provavelmente iria desistir wo curso. Chorou durante toda a conversa. Foi-lhe entao mostrado que havia preparado o paciente para enfrentar uma cirurgia, mas que não se preparara para uma 
possível intercorrência desagradável. Referiu que estava muito preocupada por estar chorando, pois, em classe the fora ensinado que uma enfermeira deveria ter controle emocional. Foi salientado que naquele momento, o paciente necessitava mais do que nunca de seus cuidados e de sua dedicação e seu choro era perfeitamente compreensfvel, por estar enfrentando uma situação nova e delicada.

A própria aluna conseguiu trazer ao grupo sua experiência e os colegas auxiliaram-na a comprender e aceitar o ocorrido.

O estado do doente agravou-se e a aluna conseguiu continuar cuidando dele até seu falecimento, ocorrido dias após. Conseguiu aceitar sua morte com tranquilidade, tendo prestado todos os cuidados necessários, continuando a dar apoio não só ao doente, como também aos familiares.

A segunda situação diz respeito a outra aluna que apresentava como problema marcante uma grande dificuldade em afastar-se do paciente grave. Na mesma proporção em que aumentava a gravidade do paciente, a estudante apresentava justificativas para manter-se ao seu lado, chegando atrazada para a seunitso de avaliacão.

Quando este fato foi trazido ao grupo, a aluna permaneceu calada e a única posiçăo tomada, foi chorar, permanecendo assim até o final da reunião.

A aluna procurou, então, a professora particularmente e disse não estar satisfeita com seu trabatho. Tentava esforçar-se ao máximo a fim de prestar todos os cuidados que considerava importantes, porém sempre permanecia a sensação que algo deixara de ser feito. Achava ser este o motivo que a impedia de afastar-se do doente, principalmente quando o falecimento era esperado a qualquer momento.

Achava que Opapitate nuteria nunca morrer; que a equipe hospitalar, principalmente médicos e enfermeiras, deveriam ser capazes de impedir a ocorrência da morte. Não sabia dizer como, mas o óbito poderia e deveria ser evitado. Durante a conversa, relatou que há algum tempo havia perdido parentes muito chegados, em acidentes fatais.

Julgou-se que a estudante năo havia conseguido compreender 
essas perdas, transferindo para os pacientes dos quais cuidava, sua problemática situacional.

A partir desse momento, em várias oportunidades, quando era observada uma repetição do comportamento da aluna, a conduta adotada era a de orientá-la no sentido de pensar sobre o ocorrido, dando-lhe assim, a oportunidade de elaborar e compreender suas atitudes. Observou-se que sua evolução foi bastante significativa, vindo a tornar-se um dos melhores elementos do grupo, principalmente em responsabilidade, refletida pela pontualidade que se tornou uma característica sua.

Outra situação a ser citada, relacionou-se aos alunos que prestavam cuidados de enfermagem a um paciente em estado muito grave, que sofreva várias intervençðes cirúrgicas e não apresentava melhora significativa. Intercalavam-se estados de ligeira melhora e piora. Sentia-se grande entusiasmo na realização do trabalho do aluno quando o paciente melhorava e muita dificuldade quando sobrevinha o estado de coma. Ele lutava contra a morte este fato foi trazido ao grupo em várias oportunidades.

No dia em que ocorreu seu falecimento, o único assunto discutido em grupo foi sua morte, percebendo-se nitidamente a decepção dos alunos. Afinal de que adiantara tanto empenho e dedicação por parte de todos se no final aquela pessoa acabara por falecer...

O objetivo deste relato seria, a nosso ver, a possibilidade do professor transmitir ao aluno, quer através de aulas de discussões em grupo ou da sua própria conduta, que os cuidados de enfermagem prestados aos pacientes moribundos ou em risco de falecer, são tão válidos quanto os ministrados àqueles que alcançam sua recuperação.

Observou-se a morte como uma constante nas situaçð̄es referidas acarretando uma atitude, por parte dos alunos, contaminada pela sensação de frustação, impotência, pena, medo e por elementos depressivos, como o choro.

O exame e a discussão das ansiedades motivadas pela morte dos pacientes, trazidas e analisadas em grupo pelos estudantes, os conduziram a uma aceitação do evento, traduzida por uma atitude mais objetiva, tranqüila, operativa e humana. 
GONÇALVES, M.M. da C. - The patient death and its reflection in a group of nursing students. Rev. Esc. Enf. USP 10 (1): 95 - 1001976.

Based upon examples, this repport shows the reflection of death in a group of nursing students and the work done to guide to a behavioral change.

\section{REFERENCIAS BIBLIOGRÁFICAS}

EISSLER, K.R. - The psychitrist and the dying patient. New York, Internacional Universities Press, 1955.

FRANCIS, G.M. \& MUNJAS, B. - Promoting psychological comfort. 4. ed. Dubuque, Brown Company, 1971.

CANNING, M. - Care of the incouncious patient. Nurs. Mirror, 9: 61-62, aug. 1974.

LEWIS, W.R. - A time to die. Nurs. Forum, 1: 7-27, 1965.

ELDER, R. - Dying in the U.S.A. Nurs. Digest, 5: 2-11, may, 1974. 